\title{
On listening: A universe of sound
}

\author{
Vanessa Tomlinson ${ }^{1}$ \\ Queensland Conservatorium, Griffith University, Brisbane, Australia.
}

\begin{abstract}
Listening, improvisation, sound and place are four words that are central to my attitude of being an artist, a musician, and a percussionist. This article spans 25 years of experiences told through ten short stories: beginning to improvise, buying a tam-tam, learning Music for 18 Musicians, not defining percussion, found objects, the Condamine Bell, performative roots, determined indeterminacy, nostalgia, and playing the tam-tam now. Together these stories begin to examine the lived experience of one Australian percussionist grappling with the unstable, dynamic pathways of percussion.
\end{abstract}

Keywords: Percussion; Listening; Improvisation; Acoustic Ecology.

\section{Introduction}

This article is based on a performative lecture, presented as a keynote address at the 2016 Australian Percussion Gathering in Brisbane, Australia. It is a series of ten two-minute talks, each punctuated by a bell manually sounded by an assistant. In presentation, the precise time-keeping nature of the bell resulted in either extended silences, or a talk being interrupted and left unfinished; but for the purposes of this paper, the entire text is included. In addition the lecture was accompanied by a sound sculpture shown in Figure 1; crushed ice embedded with peppercorns and small gravel, hung from a metal mesh cradle 1.5 metres above a floor, prepared with gongs, bowls and tiles. As the ice melted, sound making objects were released from the ice and sounded the objects below. The table of ten bells and an assistant were to my right, the ice sculpture to my left.

The thoughts that follow reveal something about my reflective moments of transformation as an artist; whether to do with taking action, being responsive, jumping in or witnessing. Together these ten talks provide the story of my journey as a percussionist, with specific attention to place, sound-making and listening.

Before the 20-minute keynote began I offered the following:

\section{Prologue}

This lecture will be presented referencing the style of John Cage's 1950s lectures, in honour of the influence of Cage's work on my evolving sensibility as a young percussionist. As an emerging percussionist in Adelaide in the late 1980s, I was first exposed to Cage's percussive Constructions (1970), which was the precursor to my fascination with found objects. Through my own research I became aware of the then recent number pieces like Two (Cage, 1987), Two2 (Cage, 1989) and One4 (Cage, 1990c). These works proposed a way of being attentive and present in performance, concepts I had not previously considered. Lastly, I discovered Cage's 1950s chance compositions, especially 27'10.554" for a percussionist (Cage, 1990a), which presented me with so many problems to solve. It was through these works that I began to explore and question important intersections between interpretation, composition and improvisation. Even more importantly, it was through these works that I began to understand how to listen. Each of the ten subjects I will discuss are defining moments in my life as a musician - steps taken that now encompass my universe of sound.

${ }^{1}$ Email: v.tomlinson@griffith.edu.au 
V. Tomlinson

Figure 1. Ice Sculpture. (C) Vanessa Tomlinson. Reproduced by permission of the author. 


\section{Improvizsation}

In 1992, I left Adelaide, Australia to study for a few months with Steven Schick at University of California, San Diego (UCSD). I was an unofficial student, so had lots of time to explore ideas. One day I stumbled in on an improvisation class. I had never knowingly improvised, and I am still not sure what made me go downstairs to a huge space, B152, with George Lewis as the teacher. I distinctly remember being called upon to improvise with a fellow student named Ellen Weller. I remember the feeling of making excuses - I don't have an instrument, I don't know what I am doing, I am just a guest - before accepting my fate and joining Ellen (flute) with a single timpani. We began playing, or more honestly we began exploring; testing sounds, dynamics, motion, gesture, proximity, voice, rhythm, histories and futures. Five minutes passed that were exhilarating, liberating, and connected me to Ellen. As far as getting to know someone, the power of improvisation had me hooked. As far as generating my own ideas, and putting them out there for real-time comment, this was a powerful moment. And as far as understanding myself as a musician and the ways in which this intermingles with my history and the experiences of others, this gave me confidence and purpose that was previously unimaginable. George Lewis had opened a door for me, simply by calmly insisting that I play. We do not move forward by making excuses, we are always accountable for our actions.

\section{My tam-tam - my universe}

In 1990 I walked into John Reynolds Drum Shop in Adelaide with my drum buddy Hej (Catherine Oates). At the back of the shop, slightly raised, was a 38 inch Paiste tam-tam. I asked the shop owner if I could hit the instrument. I was given a large white fluffy mallet and went up and struck the gong - with a similar style to Red Simmons from Hey Hey Its Saturday (for Australian viewers only). Every snare drum in the shop rattled, but I was close enough to the tam-tam to hear it transform as it decayed, to get the tiniest glimpse into its sonic potential. I wanted it. After negotiating to pay it back over the coming year, I left the shop with the tam-tam on the roof of Hej's Mini, she steering with one hand and holding the tam-tam with the other. I changed gears with one hand and held the other side on the roof. We arrived at my house, set up the tam-tam, hit it once and then sat on the couch and listened until the sound totally disappeared. This tam-tam was taken for walks to parks every weekend, as I attempted to play it as loud as it would go, wrapping my ears in scarves, beanies; and the tam-tam still not reaching its limit. With composer David Harris I took the tam-tam to a whispering wall, experimenting with the sound across the concave wall, and through the valley. Composers wrote solos for the instrument - Harris focussing on durational rolling in discreet positions (Harris, 1993), Raymond Chapman Smith (Chapman Smith, 1993) on screaming Dada poetry through the instrument picking up specific frequencies, and David Kotlowy (Kotlowy, 1993) on drawing Japanese characters with superballs on the face of the instrument. We were all obsessed by the universe of sound inside this amazing instrument. Twenty years later I travelled to a gong-making factory in Wuhan, China with Michael Askill and discovered more about gongmaking; how the Wuhan gong differs from the Paiste gong, why Paiste started making gongs in the first place. I have travelled the world for over twenty years and lost many possessions, but I still have this tam-tam.

Figure 2. My tam-tam. (C) Vanessa Tomlinson. Reproduced by permission of the author. 


\section{Tomlinson}

\section{Reich's Music for 18 Musicians}

Back in the late 1990s, I directed the first non-Reich Ensemble performance of Music for 18 Musicians (Reich, 2000) with Pat O'Keefe and an amazing team of grad students at UCSD. At first there was no available score, just a partial manuscript I found in the library, and a recording of Steve Reich and Musicians (Reich, 1987). We knew eighteen players were involved, and set about working out how to play the work from the manuscript and the recording. It was painstakingly slow, exhilarating, and incredibly interconnected. It was not just about learning notes, and after a while it was not even about learning the mechanics of how to interlock different parts. It was about listening while playing, playing while listening, and feeling. Anything else would have been pointless. We had months to put this together; it was a jigsaw puzzle with no picture. By the time we got to the last month of rehearsals a published score had come out. We were pretty close in our layout, movement of players, distribution of parts. I have always liked slowly building Reich pieces, bringing them into focus. It is as much about getting to know the individual and learning to listen together as it is about the music. The learning process affords a new way of listening.

\section{What is percussion?}

After 35 years of playing percussion I am beginning to understand what percussion is. There are dictionary definitions which point to the commonly held description that it is anything you can hit, shake or scrape. But I am fairly sure that percussion is not just an object. Even when trying to form some sort of amalgam of objects together, percussion resists being bounded, and will always surprise with new additions to the collection. Far clearer for me, is to think of percussion as an attitude, an investigation of sound. It is true that the elemental connection point of percussion is the act of striking, and that the function of percussion is fundamentally rhythmic or coloristic. But I hear you all crying, 'What about xxx? And what about xxxx?' And even without knowing what you are saying, I know you are right.

I think more of the person being a percussionist - a sound maker and explorer. Percussion is a universe of sound where nothing is excluded. I still like percussion because $I$ define my pathway through percussion, just as you define your pathway through percussion. It is a pluralistic, diverse, respectful artform. It is an innately progressive field; experimental, current, and with infinite applications. This multi-perspectival reality is central to the uniqueness of percussion.

I am not so interested in the craft of percussion, but in the way of living as a percussionist. I am interested in the creation of new work, collaboration, interdisciplinary approaches, environmental concerns, international perspectives, inter-generational art making and community building. These principles are not exclusive to percussion, but the uniquely exploratory nature of percussion with a keen focus on sound, gesture and the unknown, provides an ideal laboratory in which to explore.

\section{Found objects}

Why do I like found objects? They teach me, rather than me imposing on them. They make me attentive to my immediate environment, and aware of potential sound in objects, and this awareness of sound changes my relationship to place.

There are two parts to my practice which sits broadly under the title Music for the Banal, the Obvious, the Everyday, developed from 2009. Both parts are centred around the idea of expanding our capacity to listen - honing in on what we can hear. Hearing is an unconscious act, but to listen and cognize sound is an extremely active process, difficult in a world already saturated with so many layers of sound (Tomlinson 2011).

Listening is the central first step; listening at the site of the performance, becoming aware of the presence of sound, the effort taken to make sound, and the layering of sound from drones, to 
intermittent sound. This process tunes me into each place, and its unique acoustic signature. I often draw sound diaries of my listening, noting a mediated interpretation of the sounding environment. The second part is to then collect my objects to be used in performance. Depending on the site this can include metal, glass, plastic, ceramic or paper objects; man-made materials and often discarded waste. But the collection can also include natural objects, stones, twigs, leaves (dried or fresh) and water. Together these objects start to tell me something about my performance, reflecting weather, season and human concerns.

Together these found objects form my instrumentarium, the site of my sound making. I am literally building a new instrument for every performance with new pitch material, new spatial layout and new sonic material. Found objects are by definition unique, and it is this sonic and performative challenge that draws me to continue to work with this approach

Composers such as Cage, Cowell, Beyer and many others have long worked with found objects. Studying and performing their works has taught me that each object is unique; brake drums are not constructed to have a particular pitch, but they each have a unique pitch. What I like about found objects in these composers' work, is that pitch is the result of what is hit. Modes are the result of the combination of objects hit, constantly reconstructing the harmonic language in not just every piece, but every different performance. This accidental ordering of pitch produces surprising results - it is always interesting, and always correct. The ear tunes to the sounding material, much as the ear tunes to one's sounding environment.

\section{The Condamine bell}

Walking into the Brisbane Museum in mid 2008 to look at the ten icons of Queensland was not meant to be a musically life-changing experience. The group of artefacts - mango tree, the Ekka, the Royal Flying Doctor Service and Condamine bell among others - seemed innocent enough. But the bell was large, impressive and totally unknown to me, Head of Percussion at a major university. Thus began a story of enquiry through phone calls, new friends, and immense generosity.

My research on the Condamine bell included tangible stories: the flood on the Condamine River, when numerous drovers were stuck together with their livestock, each being able to distinguish his animals from the others by the pitch of their bells. I learnt of secret recipes for forging the bells, and the magnificent book, Cooney's Bells of the Australian Bush (2008). Drovers that bragged their bell could be heard over ten miles on a cold still night. There was a history here, fairly well documented by people on the land, drovers and bell collectors. But this history was a soundless one - the history of the animals that wore this bell to open up vast parts of Australia, and the drovers who relied on this sound to know the whereabouts of their livestock, providing money, safety and comfort on long, still winter nights under the stars. It was yet to transfer into any form of Australian musical or 'sounding' culture.

I made a project with farmers, community members, visual artists and musicians to celebrate the sounding history of the bell and the poetry and mythology that surrounds it. The event was called Sounding the Condamine (Tomlinson, 2009), and was the second of many soundings produced by Clocked Out (Griswold and Tomlinson) since 2007; site-specific, community-based exploratory investigations of sound in place.

The Condamine bell has not yet reached the symphonies of Australia; school kids certainly don't approach them at recess with white gloves, and many have said 'it sounds like just another cowbell'. But it is a bell with living makers, including Barry Doonan aged 75, who makes bells to specification, with and without dongers, helping to test the musical limits of the instrument. The local community has been reawakened to the sound of the bell. It is no longer an artefact of a past life, but an instrument with a sound and newly formed memories. This one sounding device, a 


\section{Tomlinson}

humble cowbell, has articulated a pathway from the city into the bush and back to the city again. It has a new sounded history that can be re-imagined in myriad directions. And so often that is what art does. The birthing of a new way of seeing, a new way of hearing. This humble cowbell forged by Jones in the thriving town of Condamine, was my excuse to make art.

Figure 3. Condamine Bell. (C) Vanessa Tomlinson. Reproduced by permission of the author.

\section{Roots and singularity}

Between 1990 - 1994, I was involved with a composer collective in Adelaide called Australian Contemporary Music Ensemble (ACME). This group of composers produced an astonishing amount of music, and during some periods we were presenting a concert of world premieres every week - seriously. I was not a composer then, but I was an extremely active performer on both piano and percussion. The works composed belonged mostly to the experimental music tradition, and while fully notated, were mostly concerned with careful listening to sound. The tam-tam pieces mentioned earlier were created during the ACME years, and there were concerts of marimba solos, exploring repetition, polyrhythms and extreme dynamics. There were drum concerts, again exploring the building of sound, often singular in nature. You could say we were deeply engaged in sound phenomena, but equally in ideas around form; using mathematical structures to govern large scale durations. Each week we presented a concert of experiments -the outcome of which is unknown. One work might be to repeatedly play the bottom three notes of a Bösendofer piano, in various combinations, for fifteen minutes. This piece made the piano sing, the room resonate and our brains float. These composers - David Harris, Raymond Chapman-Smith, David Kotlowy, Quentin Grant, Stephen Whittington, Phil Noack, Jason Allen, Melita White among others - were dedicated to sonic questions. This slowly changing collective was funded by the state government, and regularly recorded and broadcast by the wonderful Australian Broadcasting Commission. I have been fortunate to have had many apprenticeships during my life; this experimental ACME immersion was one.

\section{Determined indeterminacy}

I remember when learning 27'10.554” for a percussionist back in 1992, that I built an instrumentarium within the parameters requested, set about learning the score, and was then confronted by a huge problem. One particular second (") of the score, requiring more than 30 activities/icti/attacks to happen, seemed impossible to me. And each of these activities required different dynamics. My solution was to collect together the necessary amount of small to tiny rocks and pebbles, sized for dynamics and counted for the exact number of events. As the moment arose in the score I would tip these objects over my instruments to create the required density - a solution I still use today. In the composed improvisations (Cage, 1990b) I take a different approach preparing a score for not only every performance, but for every practice session so that I am learning how to read and cognise the newly constructed chance-based score in real time. I have noticed myself approaching other scores 'by the seat of my pants'; meticulously planning certain parts, but leaving one or two bars completely unlearned, trusting my performative instincts to bridge these gaps in performance.

Since the early 2000s I have been working extensively with rice and ropes. With rice, it involves both a lot of dropping on to surfaces, as well as sympathetic vibrations on things like bass drums heads in works such as Tomlinson's (2000) Practice, Griswold's (2006) Spill, Knight's (2014) Make them Dance. I can control the density of rice, the approximate starting point of the rice, but not the pathway of each rice grain. With ropes, I tether them to a point, and attach drum 
sticks to the ends of each rope, playing them like air drums. The ropes make waveforms and the trough of the wave hits the floor, or in my case, a floor prepared with found objects. In

Tomlinson/Griswold's (2007) Lavender Mist, I can control the preparations/objects on the floor, the length and strength of the rope, but I cannot control the actual resultant sound as the ropes create chaotic patterns. I have come to call this post-Cagean approach to control/uncontrol determined indeterminacy. I set up the framework with great care, and then accept the inner variations that occur in performance. Determined indeterminacy has become my favourite way of sound making.

\section{Nostalgia}

I have an exercise for you all:

Listen to the sound of your grandmother's kitchen....

(Pause for 1 minute)

listen to the sound of your father's voice.....

(Pause for 1 minute)

listen to the sound of autumn.......

(Pause for 1 minute)

When I play Globokar's ?Corporel (1989) now, I now approach it like this - listen to the sound of my head...listen to the sound of my foot...listen to the sound of my voice saying ' $\mathrm{p}$ '.

How do we listen? What is private, and what is shared? Do we actively hear in real time, or do we listen in memories? In a multi-sensorial manner? How do we hear memories? Can we hear memories?

In Nostalgia (Tomlinson, 2013) the performance is stripped bare of all intentional sound making, placing the act of sound production in the imagination of each individual performer and audience member. All are 'locating' sound - through memory, experience and context. The sonic residue discovered, and the transitional or liminal space between located, but not audible, sound forms a private listening experience for each active audience participant. This location of sound takes the listener through interesting pathways - that of memory which might require a multisensorial 'gateway' to reach the sonic layer; that of experience which will be mapped onto the geocultural specificity of each individual; and that of abstracting sound from the multi-sensorial sensation of feeling (listen to happiness for instance).

\section{The tam-tam now}

I recently returned to the tam-tam - playing solo tam-tam sets - free form improvisations now, based on different techniques, but almost always involving a slow moving and always aweinspiring crescendo, referencing the work of James Tenney. I think a lot about ownership of sounds and ideas; John Cage and silence; Tenney and the tam-tam crescendo; Alvin Lucier and the triangle. With no disrespect, I cannot pass them complete copyright of these ideas - these things exist within the instruments and within us. Silence, the power of a tam-tam, and the sonic phenomena of a triangle are part of the journey of sonic exploration, there to be discovered again and again by each individual in ever-varying ways. It is the discovery of these moments that make them amazing, the arrival at the place where instrument, idea, person, and place all contribute to that artistic moment.

These days I don't like playing any tam-tam, just mine. I have learnt this instrument like a violinist learns their instrument. I know exactly how to coax sound out of it, bring out particular harmonics, filter the sound, stop the sound. After 26 years with this instrument, you can hear my history through these improvisations. The only thing you can do with a tam-tam is listen to it. As 


\section{Tomlinson}

one of the Gyoto Monks said in a talk at the Queensland Conservatorium recently, 'we only need a glimpse of the entire universe to know it is there'. Once you have lived with a tam-tam, you have glimpsed a universe of sound.

\section{Acknowledgements}

I would like to acknowledge the support of Queensland Conservatorium, Griffith University and the Queensland Conservatorium Research Centre in supporting the Australian Percussion Gathering 2016, alongside Just Percussion, Yamaha and Optimum Percussion.

\section{Biography}

Vanessa Tomlinson is active in the fields of solo percussion, improvisation, installation, site-specific performance and composition. She is currently Associate Professor in Music at Queensland Conservatorium, Griffith University and Deputy Director of the Queensland Conservatorium Research Centre. In addition Vanessa is the co-artistic director of Clocked Out - one of Australia's most important and eclectic arts organisations - and Artistic Director of the Australian Percussion Gathering (2010,2016), Transplanted Roots: Research in International Percussive Arts (2017) and Sounding Harrigans Lane (2014-17). Over the years Vanessa has commissioned, inspired and premiered more than 100 works, worked alongside countless wonderful improvisers, and collaborated with artists across the globe.

\section{References}

Cage, J. (1960). 4'33": Tacet, any instrument or combination of instruments. Frankfurt a.M.: Edition Peters.

Cage, J. (1961). Silence. Middletown: Wesleyann University Press.

Cage, J. (1970). Third construction: 4 percussion players. New York: Henmar Press.

Cage, J. (1989). Two2: For 2 pianos. New York: Edition Peters.

Cage, J. (1987). Two: Parts for flute and piano. New York: Edition Peters.

Cage, J. (1990a). 27' 10.554": For a percussionist. New York: Edition Peters.

Cage, J. (1990b). C composed improvisation: For snare drum alone. New York, NY: Henmar Press.

Cage, J. (1990c). One4: For solo drummer. New York: Edition Peters.

Chapman-Smith, R. (1993) Reply the Night [score]. Self-published.

Cooney, D. (2008). Bells of the Australian Bush. Toowoomba: Jinglestix.

Globokar, V. (1989). ?Corporel: Für einen Schlagzeuger auf seinem Körper. Frankfurt: Peters.

Griswold, E., Tomlinson, V. (2008). Lavendar Mist, Foreign Objects [CD]. Brisbane: Clocked Out 005.

Griswold, E. (2007). Spill [score]. Self-published.

Harris, D. (1993). Tam Tam 12.8.93. [score]. Self published.

Knight, P. (2014). Make them dance [score]. Self published

Kotlowy, D. (1993). Untitled. [score]. Self-published. 
Lucier, Alvin (1988). Silver Streetcar for the Orchestra: Solo for amplified triangle. Kiel: Material Press.

Reich, S. (2000). Music for 18 musicians: For ensemble. New York: Boosey \& Hawkes.

Reich, S. (1987). Music for 18 musicians [CD]. München: ECM Records.

Tenney, J. (1997). Having never written a note for percussion: For any percussion instrument(s). Baltimore: Smith Publications.

Tomlinson, V. (2000). Practice, Every Night the Same Dream [CD]. Melbourne: Clocked Out 001

Tomlinson, V., Davis, S (ed.) 2013. Music for the Banal, the Obvious, the Everyday. Future nature, future culture(s): Peer-reviewed papers for Balance - Unbalance 2013 International Conference, May 31 - June 2, 2013, Noosa, Australia, Noosa Biosphere Limited \& CQUniversity Noosa, Noosa, Qld., http://hdl.cqu.edu.au/10018/938596

Tomlinson, V. (2009). Sounding the Condamine. Retreived from http://vanessatomlinson.com/writing.html\#condamine

Tomlinson, V. (2011). Music for the banal, the obvious, the everyday. Retrieved from http://vanessatomlinson.com/writing/tomlinson_music_for_the_banal.pdf

Tomlinson, V. (2013). Nostalgia [score]. Self-Published. 